\title{
Blue emitting gold nanoclusters templated by poly-cytosine DNA at low pH and poly-adenine DNA at neutral pH
}

\author{
Received 20th April 2012, Accepted 15th May 2012 \\ DOI: $0.1039 / \mathrm{c} 2 \mathrm{cc} 32841 \mathrm{k}$
}

Thomas A.C. Kennedy, James L. MacLean, and Juewen Liu*a

Blue fluorescent gold nanoclusters were prepared in the presence of poly-cytosine DNAs at low pH and poly-adenine at neutral $\mathrm{pH}$ using citrate as the reducing agent; various buffer conditions affecting the synthesis have been explored.

Few atom noble metal nanoclusters (NCs) have emerged as a useful class of materials for biosensing, imaging and catalysis. ${ }^{1}$ These NCs possess discrete energy states similar to molecular fluorophores. Compared to semiconductor quantum dots, $\mathrm{Au}$ and $\mathrm{Ag}$ NCs have fewer toxicity concerns. Their 15 synthesis usually requires strong polymeric or chelating ligands to avoid the growth of larger nanocrystals. AuNCs have been prepared in the presence of thiol compounds, ${ }^{2}$ dendrimers, ${ }^{3-5}$ peptides, ${ }^{6}$ and proteins. ${ }^{7}$ Many AgNCs were obtained using cytosine-rich DNAs. Taking advantage of the binding interaction between silver and cytosine, ${ }^{8}$ a diverse range of emission colors have been achieved using different DNA sequences. ${ }^{9}$ DNA templated synthesis has a number of advantages. First, in addition to serving as a template, DNA possesses functional roles for molecular recognition (e.g. aptamers). ${ }^{10}$ With appropriately designed DNA sequences, it is possible to directly couple analyte binding with fluorescence signaling. ${ }^{11}$ Second, since DNA is much smaller compared to proteins, the associated NCs are not deeply shielded, allowing more effective energy transfer to other fluorophores and quenchers. Third, chemical synthesis of DNA allows for a large degree of versatility in DNA sequence and modification, facilitating fundamental studies and practical applications. Finally, unlike many synthetic polymers, DNA is non-toxic with good biocompatibility.

Compared to AgNCs, AuNCs might be more stable since gold is less easily oxidized. ${ }^{12}$ However, DNA-templated AuNCs have not been reported. Based on current knowledge, DNA needs to bind strongly to gold precursors and AuNCs (Figure 1A). The most commonly used gold source is $\mathrm{HAuCl}_{4}$. Since DNA, $\mathrm{AuCl}_{4}$ and gold nanoparticles are negatively charged, we reason that a favorable interaction might be achieved at low $\mathrm{pH} .{ }^{13}$ In addition, the ratio between gold and DNA may also be important.
Since there is almost no information on the interaction between DNA and AuNCs, we first tested several DNA homopolymers; $\mathrm{A}_{30}, \mathrm{~T}_{30}$ and $\mathrm{C}_{30}$ were chosen for this purpose. The reaction was carried out using $100 \mu \mathrm{M} \mathrm{HAuCl}_{4}$ and $50 \mu \mathrm{M}$ DNA at $\mathrm{pH}$ 3-7 using citrate as buffer and reducing agent. After overnight incubation, $\mathrm{C}_{30}$ produced blue fluorescent AuNCs under $245 \mathrm{~nm}$ UV light excitation (Figure 1B). The fluorescence was more intense with lower $\mathrm{pH}$ and the fluorescence excitation spectrum shows two peaks at $275 \mathrm{~nm}$ and $360 \mathrm{~nm}$ (Figure 1D). Since exciting either peak generated the identical emission spectral shape, both wavelengths should excite the same electronic transition of the AuNC. Since the absorption maximum of poly-C DNA is at $275 \mathrm{~nm}$, it is likely that the $275 \mathrm{~nm}$ excitation peak is due to energy transfer from cytosine to AuNC, ${ }^{14}$ which also suggests that the AuNCs were associated with the DNA. Therefore, the direct excitation wavelength should be $360 \mathrm{~nm}$, yielding a Stokes shift of $\sim 80 \mathrm{~nm}$ for the $440 \mathrm{~nm}$ emission peak, which is consistent with the literature reported value for blue emitting AuNCs. ${ }^{3}$ Its UV-vis absorption spectrum also shows a strong peak at $360 \mathrm{~nm}$ due to AuNC absorption (see Figure S1 of ESI). There is also a very weak surface plasmon band at $\sim 540 \mathrm{~nm}$. Transmission electron microscopy data showed that the maximal $\mathrm{Au}$ size is $\sim 2 \mathrm{~nm}$ (Figure S2), consistent with the weak surface plasmon peak. Blue emitting AuNCs are too small to be resolved.

Using $275 \mathrm{~nm}$ excitation, the emission spectra from different DNA sequences at $\mathrm{pH} 3$ were collected (Figure 1E). $\mathrm{A}_{30}$ produced very weak fluorescence whose intensity was only $\sim 10 \%$ of that with $\mathrm{C}_{30}$, while $\mathrm{T}_{30}$ produced almost no fluorescence. The samples were also observed under ambient light and we found that some of the $\mathrm{T}_{30}$ samples were red (Figure 1C, e.g. from $\mathrm{pH} 4-6$ ), indicating the formation of relatively large AuNPs exhibiting the surface plasmon effect. In the absence of DNA, no fluorescent AuNCs were produced while purple Au nanoparticles were found to stick to the tubes (see arrow heads of Figure 1C). Therefore, DNA sequence and $\mathrm{pH}$ are important for producing fluorescent AuNCs. Poly-A DNA is known to interact with the AuNP surface strongly. ${ }^{15,16}$ Although $\mathrm{A}_{30}$ failed to produce fluorescent AuNCs in this case, a careful optimization of the ratio between $\mathrm{Au}$ and DNA yielded highly fluorescence AuNCs (vide infra). 
To quantitatively test the effect of $\mathrm{pH}$, we diluted the AuNCs in Figure $1 \mathrm{~B}$ with water and the highest fluorescence was observed at pH 3 (Figure 1F). Reducing pH further to 2 showed slightly reduced emission. Fluorescence dropping and emission peak broadening were observed at higher $\mathrm{pH}$. C-rich DNAs have been often used to prepare fluorescent $\mathrm{AgNCs}$ at neutral $\mathrm{pH}$ since $\mathrm{Ag}^{+}$can tightly bind to the $\mathrm{N} 3$ nitrogen of cytosine. ${ }^{8}$ Crystallographic data also showed a similar binding between $\mathrm{AuCl}_{4}{ }^{-}$and 1-methylcytosine. ${ }^{17}$ Since the $p K_{a}$ of cytosine is 4.2 , the $\mathrm{N} 3$ position is protonated at $\mathrm{pH} 3$ and is unlikely to contribute to gold binding. Binding of copper by the keto oxygen of cytosine at low $\mathrm{pH}$ was observed, ${ }^{18}$ which may also explain the binding of gold in our work (Figure S3). The above fluorescence measurements were performed at the $\mathrm{pH}$ where AuNCs were synthesized. We next diluted AuNCs from the same stock sample into buffers at various $\mathrm{pH}$ (Figure $1 \mathrm{G}$ ). The fluorescence intensity barely changed from $\mathrm{pH} 3$ to 6 , and a drop was observed at higher $\mathrm{pH}$, indicating that these $\mathrm{C}_{30}$ templated AuNCs are highly stable at acidic conditions.
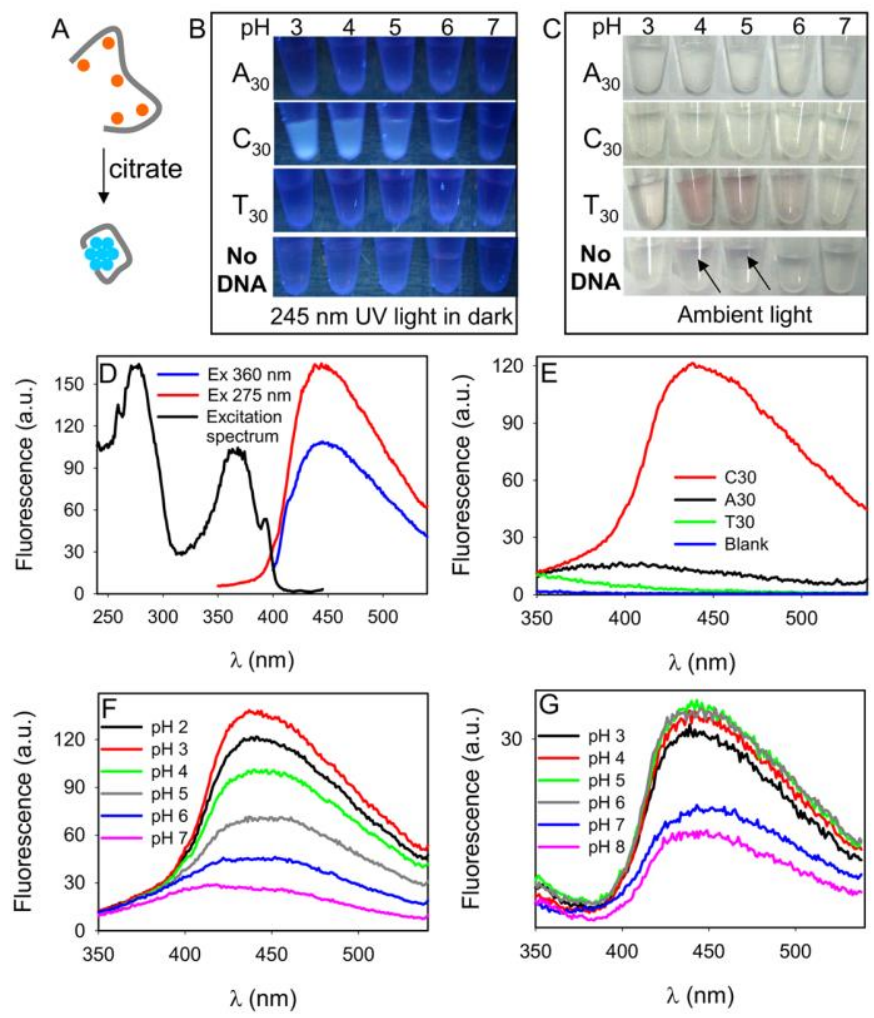

Figure 1. (A) A scheme of DNA templated AuNC synthesis. Fluorescence (B) and optical (C) graphs of $\mathrm{DNA} / \mathrm{HAuCl}_{4}$ mixture at various $\mathrm{pH}$ citrate buffer after overnight incubation. The arrow heads in (C) point to AuNPs sticking to the tube surface. (D) Fluorescence emission and excitation spectra of AuNCs templated by $\mathrm{C}_{30}$. The feature at $\sim 390 \mathrm{~nm}$ of the excitation spectrum is from water Raman scattering. Fluorescence spectra of AuNCs templated by various DNAs at $\mathrm{pH} 3$ (E) or by $\mathrm{C}_{30}$ at various $\mathrm{pH}$ (F). (G) AuNC fluorescence as a function of $\mathrm{pH}$.
For most previous work, $\mathrm{NaBH}_{4}$ was used as the reducing agent, which is unstable and needs to be freshly prepared. Alternatively, the native reducing property of proteins have also been harnessed. ${ }^{7}$ In this work, citrate was used and the kinetics of fluorescence generation was monitored. In the first $2 \mathrm{hrs}$, the signal reached $\sim 70 \%$ of the final intensity and it took $\sim 8 \mathrm{hrs}$ to reach stable fluorescence (Figure S4). Next we studied the effect of citrate concentration (Figure 2A), where fluorescence decreased at lower citrate concentrations. Since citrate was used also as a buffer, to compensate the possible $\mathrm{pH}$ change, we tested another sample with $20 \mathrm{mM}$ phosphate buffer $(\mathrm{pH} 3)$ and $1 \mathrm{mM}$ citrate, which produced a stronger fluorescence intensity than the sample with just $1 \mathrm{mM}$ citrate, but the intensity was still weaker than that with $50 \mathrm{mM}$ citrate. Therefore, to achieve high fluorescence, a high citrate concentration is needed.

In the above work, the $\mathrm{C}_{30}$ :Au ratio was $1: 2$, which means that the cytosine:Au ratio was 15:1. To further optimize the synthesis, we fixed the $\mathrm{HAuCl}_{4}$ concentration and varied the DNA added (Figure 2B). The higher the $\mathrm{C}_{30}$ concentration, the stronger the fluorescence. This is different from the case of using $\mathrm{C}$-rich DNA for AgNC synthesis, where a DNA: $\mathrm{Ag}^{+}$ratio of 1:6 is often used (cytosine: $\mathrm{Ag}^{+} \cong 2: 1$ ). Our experiment suggests that the binding between cytosine and gold at $\mathrm{pH} 3$ might be weaker than that with $\mathrm{Ag}$ at neutral $\mathrm{pH}$. We next prepared AuNCs and AgNCs using $\mathrm{C}_{30}$ separately and the AuNCs were more resistant to photobleaching (Figure S5).
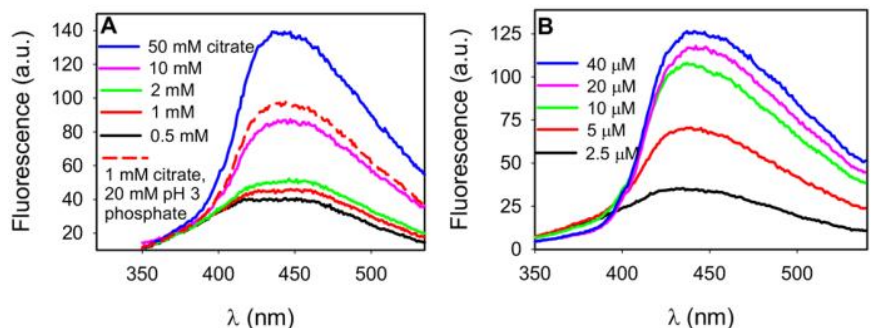

C
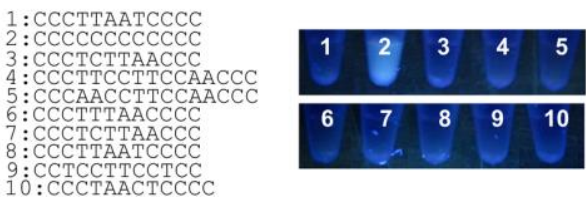

Figure 2. AuNC fluorescence spectra as a function of citrate concentration (A) and $\mathrm{C}_{30}$ DNA concentration (B). (C) Photograph of AuNCs synthesized by various $C$-rich DNAs under UV excitation.

Since AgNCs with various emission colors were produced using different DNA sequences, to test whether this is true for AuNCs, we tested a number of C-rich DNAs that were reported to produce different AgNCs (Figure 2C). ${ }^{9}$ However, only DNA2 with its sequence being $\mathrm{C}_{12}$ produced bright fluorescence (Figure S6), which was even stronger than that with $\mathrm{C}_{30}$. This study shows that the optimal DNA should be short polycytosine. 
Since $\mathrm{A}_{30}$ also showed weak fluorescence in Figure 1E, next we aim to optimize its synthesis condition. Using $50 \mathrm{mM} \mathrm{pH} 7$ citrate buffer, we fixed $\mathrm{HAuCl}_{4}$ to be $150 \mu \mathrm{M}$ and varied $\mathrm{A}_{30}$ from 0.5 to $8 \mu \mathrm{M}$. The highest fluorescence was observed with $4 \mu \mathrm{M} \mathrm{A}_{30}$ (Figure 3A), where the ratio between adenine and $\mathrm{HAuCl}_{4}$ was around $1: 1$. Therefore, the reason for the failure to observe fluorescent AuNCs using $\mathrm{A}_{30}$ in Figure 1B was due to the too high DNA concentration. This binding stoichiometry suggests the high affinity between adenine and gold. We next fixed $\mathrm{A}_{30}$ at $4 \mu \mathrm{M}$ and varied $\mathrm{HAuCl}_{4}$ concentration. The highest fluorescence was observed with $100-150 \mu \mathrm{M} \mathrm{HAuCl}_{4}$ (Figure 3C). A further increase of $\mathrm{HAuCl}_{4}$ produced red/purple colored nanoparticles. Next the effect of $\mathrm{pH}$ was tested and the highest fluorescence was observed using an $\mathrm{A}_{30}: \mathrm{HAuCl}_{4}$ ratio of $1: 30$ at $\mathrm{pH}$ 6 (Figure 3B), where adenine was not protonated. The decreased fluorescence at lower $\mathrm{pH}$ suggests that gold binding might involve the $\mathrm{N} 7$ position of adenine (Figure S3), whose $p K_{a}$ is $\sim 3.5$. The optimal citrate concentration was determined to be $50 \mathrm{mM}$ or higher (Figure S7). A photograph was also taken for the $\mathrm{pH}$ samples (Figure 3D). Interestingly, we observed a slight red fluorescence at $\mathrm{pH} 4$. The synthesis of AuNCs at various $\mathrm{pH}$ in the presence of pepsin was recently reported, where a broad range of emission colors were obtained..$^{19}$

The AuNCs prepared with $\mathrm{A}_{30}$ has a slightly longer emission peak centered at $\sim 480 \mathrm{~nm}$ (Figure 3E). The 5 excitation spectrum shows a peak at $280 \mathrm{~nm}$, which is $20 \mathrm{~nm}$ longer than the absorption peak of poly-A DNA. To understand this, we measured the absorption spectra of the sample and the absorption maximum was at $270 \mathrm{~nm}$ (Figure S8), similar to the excitation peak. The small peak $413 \mathrm{~nm}$ was mainly due to the water Raman scattering, where water alone can generate the same feature.
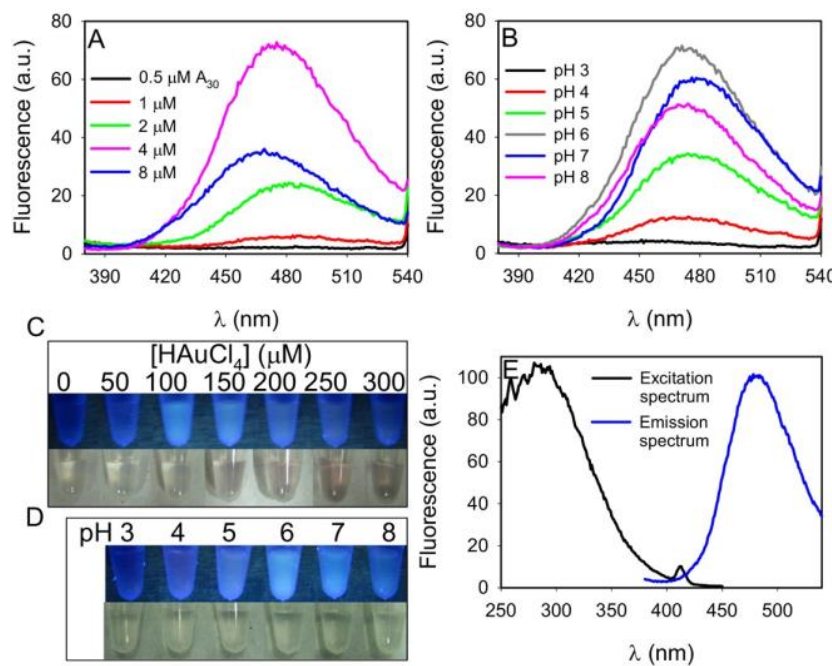

Figure 3. Fluorescence spectra of AuNCs synthesized using various concentrations of $\mathrm{A}_{30}$ at $\mathrm{pH} 7$ (A) and using different $\mathrm{pH}(\mathrm{B})$. [ $\left.\mathrm{HAuCl}_{4}\right]=150$ $\mathrm{QM}$ for all the samples. Photographs of AuNCs synthesized with increasing $\mathrm{HAuCl}_{4}$ concentration (C) and at various $\mathrm{pH}$ (D). (E) Fluorescence emission and excitation spectra of AuNCs templated by $\mathrm{A}_{30}$.

While DNA has been used to control the synthesis of AuNPs, ${ }^{20,21}$ this is the first report on making fluorescent AuNCs. This study has revealed the binding interaction between gold and cytosine at low
$\mathrm{pH}$. This interaction is weaker than that between silver and cytosine but still strong enough to allow controlled reduction of $\mathrm{HAuCl}_{4}$. Poly-A DNA requires a more strict control of the ratio with $\mathrm{HAuCl}_{4}$ and it works better at around neutral $\mathrm{pH}$, where adenine is not protonated. These AuNCs can receive energy from nucleobases to boost their emission intensity. The resulting AuNCs could be used for various analytical and biomedical applications. Future work will be focused on optimizing DNA sequences and synthesis conditions to further improve quantum yield and to achieve other emission colors.

Funding for this work is from the University of Waterloo, the Canadian Foundation for Innovation, and the Natural Sciences and Engineering Research Council (NSERC) of Canada and the Early Researcher Award from the Ontario Ministry of Research and Innovation.

\section{Notes and references}

Department of Chemistry, Waterloo Institute for Nanotechnology, University of Waterloo, Waterloo, Ontario, N2L 3G1, Canada. Fax: 519 7460435; Tel: 5198884567 Ext.38919; E-mail: liujw@uwaterloo.ca.

Electronic Supplementary Information (ESI) available: materials and methods, TEM micrograph, additional UV-vis and fluorescence spectra, kinetics, and gold/DNA interactions. See DOI...

1. J. Zheng, P. R. Nicovich and R. M. Dickson, Annu. Rev. Phys. Chem., 2007, 58, 409; (b) R. C. Jin, Nanoscale, 2010, 2, 343; (c) J. F. Parker, C. A. Fields-Zinna and R. W. Murray, Acc. Chem. Res., 2010, 43, 1289; (d) L. Shang, S. J. Dong and G. U. Nienhaus, Nano Today, 2011, 6, 401.

2. Z. Wu and R. Jin, Nano Lett., 2010, 10, 2568.

3. J. Zheng, C. Zhang and R. M. Dickson, Phys. Rev. Lett., 2004, 93, 077402.

4. R. C. Hedden, B. J. Bauer, A. Paul Smith, F. Grohn and E. Amis, Polymer, 2002, 43, 5473

5. Y. Bao, C. Zhong, D. M. Vu, J. P. Temirov, R. B. Dyer and J. S. Martinez, J. Phys. Chem. C, 2007, 111, 12194.

6. T. G. Schaaff and R. L. Whetten, J. Phys. Chem. B, 2000, 104, 2630.

7. J. P. Xie, Y. G. Zheng and J. Y. Ying, J. Am. Chem. Soc., 2009, 131, 888; (b) L. Yan, Y. Q. Cai, B. Z. Zheng, H. Y. Yuan, Y. Guo, D. Xiao and M. M. F. Choi, J. Mater. Chem., 2012, 22, 1000; (c) Z. Q. Yuan, M. H. Peng, Y. He and E. S. Yeung, Chem. Comm., 2011, 47, 11981; (d) C. L. Liu, H. T. Wu, Y. H. Hsiao, C. W. Lai, C. W. Shih, Y. K. Peng, K. C. Tang, H. W. Chang, Y. C. Chien, J. K. Hsiao, J. T. Cheng and P. T. Chou, Angew. Chem. Int. Ed., 2011, 50, 7056; (e) X. Le Guevel, N. Daum and M. Schneider, Nanotechnology, 2011, 22, 275103; (f) P. L. Xavier, K. Chaudhari, P. K. Verma, S. K. Pal and T. Pradeep, Nanoscale, 2010, 2, 2769; (g) F. Wen, Y. H. Dong, L. Feng, S. Wang, S. C. Zhang and X. R. Zhang, Anal. Chem., 2011, 83, 1193; (h) X. Le Guevel, B. Hotzer, G. Jung, K. Hollemeyer, V. Trouillet and M. Schneider, J. Phys. Chem. C, 2011, 115, 10955.

8. Ono, S. Cao, H. Togashi, M. Tashiro, T. Fujimoto, T. Machinami, S. Oda, Y. Miyake, I. Okamoto and Y. Tanaka, Chem. ${ }_{75}$ Comm., 2008, 4825.

9. J. T. Petty, J. Zheng, N. V. Hud and R. M. Dickson, J. Am. Chem. Soc., 2004, 126, 5207; (b) C. I. Richards, S. Choi, J.-C. Hsiang, Y. Antoku, T. Vosch, A. Bongiorno, Y.-L. Tzeng and R. M. Dickson, J. Am. Chem. Soc., 2008, 130, 5038; (c) E. G. Gwinn, P. ${ }_{80}$ O'Neill, A. J. Guerrero, D. Bouwmeester and D. K. Fygenson, Adv. Mater., 2008, 20, 279; (d) G. Y. Lan, W. Y. Chen and H. T. Chang, Rsc Advances, 2011, 1, 802; (e) B. Y. Han and E. K. Wang, Anal. 
Bioanal. Chem., 2012, 402, 129; (f) W. Y. Chen, G. Y. Lan and H. T. Chang, Anal. Chem., 2011, 83, 9450.

10. J. Liu, Z. Cao and Y. Lu, Chem. Rev., 2009, 109, 1948.

11. W. W. Guo, J. P. Yuan, Q. Z. Dong and E. K. Wang, J. Am. Chem. Soc., 2010, 132, 932; (b) L. Deng, Z. X. Zhou, J. Li, T. Li and S. J. Dong, Chem. Comm., 2011, 47, 11065; (c) T. Li, L. B. Zhang, J. Ai, S. J. Dong and E. K. Wang, ACS Nano, 2011, 5, 6334. (d) W. W. Guo, J. P. Yuan and E. K. Wang, Chem. Comm., 2011, 47, 10930; (e) H. C. Yeh, J. Sharma, J. J. Han, J. S. Martinez and J. H. Werner, Nano Lett., 2010, 10, 3106; (f) J. J. Yin, X. X. He, K. M. Wang, Z. H. Qing, X. Wu, H. Shi and X. H. Yang, Nanoscale, $2012,4,110$.

12. M. Ritchie, K. R. Johnsen, J. R. Kiser, Y. Antoku, R. M. Dickson and J. T. Petty, J. Phys. Chem. C, 2007, 111, 175.

13. X. Zhang, M. R. Servos and J. Liu, Langmuir, 2012, 28, 3896; (b) X. Zhang, M. R. Servos and J. Liu, J. Am. Chem. Soc., 2012, 134, 7266.
14. P. R. O'Neill, E. G. Gwinn and D. K. Fygenson, J. Phys. Chem. C, 2011, 115, 24061.

15. J. J. Storhoff, R. Elghanian, C. A. Mirkin and R. L. Letsinger, Langmuir, 2002, 18, 6666.

16. H. Kimura-Suda, D. Y. Petrovykh, M. J. Tarlov and L. J. Whitman, J. Am. Chem. Soc., 2003, 125, 9014.

17. M. S. Holowczak, M. D. Stancl and G. B. Wong, J. Am. Chem. Soc., 1985, 107, 5789.

18. S. Shirotake and T. Sakaguchi, Chem. Pharm. Bull., 1977, 25, 3232 .

19. H. Kawasaki, K. Hamaguchi, I. Osaka and R. Arakawa, Adv Funct. Mater., 2011, 21, 3508.

20. Z. Wang, J. Zhang, J. M. Ekman, P. J. A. Kenis and Y. Lu, Nano Lett., 2010, 10, 1886.

21. L. Xu, Y. Zhu, W. Ma, W. Chen, L. Liu, H. Kuang, L. Wang and C. Xu, J. Phys. Chem. C, 2011, 115, 3243. 